\title{
Pituitary adenylate-cyclase-activating polypeptide (PACAP): another novel target for treatment of primary headaches?
}

\author{
Messoud Ashina ${ }^{1 *}$ and Paolo Martelletti ${ }^{2,3}$
}

Since its discovery in 1989 [1], pituitary adenylate cyclase activating peptide (PACAP) has emerged as a key molecule in primary headaches. New insights on the role of PACAP in migraine [2] have now been translated into interest in exploring the migraine preventative effect of monoclonal antibodies against PACAP and monoclonal antibodies against PAC1 receptor (https://clinicaltrials.gov/ ct2/show/NCT03238781?term=AMG301\&rank $=1 ;[3]$ ).

Given that PACAP is a multifunctional peptide involved in various cellular and physiological responses, it is important to understand and further explore its function in non-headache mechanisms which might be relevant in context to primary headaches. This TJHP thematic series provide an overview of the history of the discovery of PACAP and its three receptors [4] and summarize PACAP and its receptor distribution in migraine relevant structures [5]. Furthermore, the readers will get insights on the role of PACAP in regulating the production of inflammatory mediators [6] and important role of degranulation of dural mast cells via a yet unknown receptor in migraine induction by PACAP38 [7]. The series also cover possible mechanisms of PACAP38induced migraine, outline future directions [8] and discuss how PACAP may cross the blood brain barrier [9] and its implication for PACAP induced migraine. To further elucidate the role of PACAP in primary headaches it is important to study its role in regulation of sleep [10] and vascular tone [11] which are covered by excellent review articles in the special issue Both aspects are important in context of tolerability and safety of future anti PACAP drugs for prevention of primary headaches. Altogether our aim is to provide a comprehensive series of reviews focusing on PACAP as an emerging molecule in primary headache headaches.

\footnotetext{
* Correspondence: ashina@dadlnet.dk

'Department of Neurology, Danish Headache Center, Rigshospitalet Glostrup, Faculty of Health and Medical Sciences, University of Copenhagen,

Copenhagen, Denmark

Full list of author information is available at the end of the article
}

\section{Publisher's Note}

Springer Nature remains neutral with regard to jurisdictional claims in published maps and institutional affiliations.

\author{
Author details \\ ${ }^{1}$ Department of Neurology, Danish Headache Center, Rigshospitalet Glostrup, \\ Faculty of Health and Medical Sciences, University of Copenhagen, \\ Copenhagen, Denmark. ${ }^{2}$ Department of Clinical and Molecular Medicine, \\ Sapienza University, Rome, Italy. ${ }^{3}$ Regional Referral Headache Centre, \\ Sant'Andrea Hospital, Rome, Italy.
}

Received: 18 April 2018 Accepted: 19 April 2018

Published online: 08 May 2018

References

1. Miyata A, Jiang L, Dahl RD et al (1990) Isolation of a neuropeptide corresponding to the $\mathrm{N}$-terminal 27 residues of the pituitary adenylate cyclase activating polypeptide with 38 residues (PACAP38). Biochem Biophys Res Commun 170:643-648

2. Vollesen ALH, Amin FM, Ashina M. Targeted pituitary adenylate cyclaseactivating peptide therapies for migraine. Neurotherapeutics 2018. https://doi.org/10.1007/s13311-017-0596-x. [Epub ahead of print] Review. PubMed PMID: 29464574

3. Robust development pipeline [Internet]. 2017 [cited 2017 Feb 27]. http:// www.alderbio.com/therapeutics/pipeline/

4. Hirabayashi T, Nakamachi T, Shioda S (2018) Discovery of PACAP and its receptors in the brain. J Headache Pain 5:19. https://doi.org/10.1186/s10194-0180855-1

5. Edvinsson L, Tajti J, Szalárdy L, Vécsei L (2018) PACAP and its role in primary headaches. J Headache Pain. 9:19. https://doi.org/10.1186/s10194-018-0852-4

6. Waschek JA, Baca SM, Akerman S (2018) PACAP and migraine headache: immunomodulation of neural circuits in autonomic ganglia and brain parenchyma. J Headache Pain. 13:19. https://doi.org/10.1186/s10194-018-0850-6

7. Jansen-Olesen I, Hougaard PS (2018) PACAP and its receptors in cranial arteries and mast cells. J Headache Pain. 20:19. https://doi.org/10.1186/ s10194-017-0822-2

8. Ashina H, Guo S, Vollesen ALH, Ashina M (2017) PACAP38 in human models of primary headaches. J Headache Pain. 23:18. https://doi.org/10.1186/ s10194-017-0821-3

9. Amin FM, Winther Schytz H. Transport of the pituitary adenylate cyclaseactivating polypeptide across the blood-brain barrier: implications for migraine.

10. Holland PR, Barloese M, Fahrenkrug J (2018) PACAP in hypothalamic regulation of sleep and circadian rhythm: importance for headache. J Headache Pain. 5:19. https://doi.org/10.1186/s10194-018-0844-4

11. Reglodi D, Vaczy A, Rubio-Beltran E et al. Protective effects of PACAP in ischemia. J Headache Pain. 2018; 19. https://doi.org/10.1186/s10194-018-0845-3 